\title{
TRANSFER OF TRANSGENERATIONAL INFORMATION AND THE POSSIBILITY OF THEIR MEASUREMENT AND/OR MONITORING
}

\author{
By Prof. Dr. MIRJANA SOVILJ
}

\section{Affiliations:}

1. Life Activities Advancement Center, Belgrade, Serbia

2. Institute for Experimental Phonetics and Speech Pathology, Belgrade, Serbia

Author's email: iefpgmir@gmail.com

\begin{abstract}
An holistic approach to studies in human development, communication and behavior is an imperative for modern science. This process can be observed as a complex system of mutually conditioned physical, mental, emotional and spiritual processes, which are the expression of astro-geophysical, climatic, socio-biological and psychophysiological processes and sub-processes developed through phylogenetic and ontogenetic sequence, and later throughout the whole life. Holistic studies of human system developmental characteristics enable more complex and more precise perception of a large number of phenomena associated with the functioning of human systems: heritage - environment - behavior, which contribute to the promotion of the stated system self-management improvement and its directing towards the basic goal optimization of the system on all levels: physical, mental, emotional and spiritual.

In order to achieve this goal, it is necessary to raise awareness of the role which transgenerational and transpersonal influences of an individual have on their offspring (with the emphasis on parents - children relations). At the same time, it is necessary to raise competence of various professions dealing with development, health and education of children and young people, in regard to the prevention of all forms of prenatal and birth traumas which have far-reaching consequences in an individual's behavior throughout life, including a wider community. In order to successfully realize these goals, it is necessary with the help of mass media, to increase knowledge and awareness regarding responsible parenthood from the earliest to the oldest age.
\end{abstract}

Key words: prenatal development, PHS, speech and language, behavior, learning, drawing, emotions, mass media 


\section{INTRODUCTION}

A contemporary view requires change in the way we think which is necessary and imperative if we want the world to continue developing and evolving. Therefore, we need to correct some of the deepest mental representations about the world and human interaction with nature. (Dent, E.B.1999). This interaction creates the feedback by which the system indirectly and/ or directly influences its future states and activities. These dynamic interactions and their feedback provide evolution and permanence of emergent systems, such as socio-biophysical or integral natural and social systems. That is why an holistic approach to the study of human communication and behavior, is an imperative for modern science.

Human communication and behavior can be observed as a complex system with sets of mutually conditioned physical, mental, emotional and spiritual processes, which are the expression of astro-geophysical, climatic, socio-biological and psycho-physiological processes and sub-processes developed through phylogenetic and ontogenetic sequence, and later on throughout the whole life. In this system, certain processes are determined: anatomical morphological development from a zygote to a newborn; the very functioning of this system is stochastic or randomly determined. Human communication with self and the surroundings and behavior do not follow a strictly determined law, but rather depend on a large number of mutually correlated factors which constitute the continuously stable, and at the same time, variable system. In order to provide continuity of optimal development of this system it is necessary to constantly maintain balance of freedom and arrangement i.e. by flexible reacting and moderate centralization (Uskoković, 2006).

Holistic studies of characteristics enable more complex and precise perception of a large number of phenomena associated with the functioning of the human - communication and behavior - which contributes to the promotion of the development of selfmanagement of the stated system and its directing towards the basic goal - optimization of the system on all levels: physical, mental, emotional and spiritual. Optimization of the development of this system requires studying and monitoring from the moment of conception, through the period of prenatal development, to birth and growing up. In order to achieve this goal it is necessary to raise scientific awareness of the roots of human communication and behavior as an expression of ancestral heritage, through a unique birth of a human being until the development of a truly distinctive personality and Being as an expression of the highest degree of the synchronicity of the cosmic and personal Self. The promotion of the human communication and behavior lies in the complete synchronization of cosmic, spiritual, mental, emotional and physical potentials of his development.

The questions "Who are we? ", "Where do we come from? ", "Where do we go?" are as old as humanity. This paper will not attempt to answer these questions, but rather to represent the results of scientific research which can offer an angle of observation and perception of interconnections and inter- dependencies of the development of human communication and behavior. Let us start with the hypothesis that the human is created out of an emotion. It is only natural that it should be Love, but unfortunately, it is not always so. Research in the area 
of prenatal psychology indicates that it is often: passion, fear, hostility, greed, jealousy, rage, envy, anger, etc. In the pre-conceptual and conceptual period these emotions basically define human behavior and communication throughout life by a very extended form of learning during which association (psychological connection) is established between the stimulus and its consequences.

Besides anatomical development of organs and physiological systems and their functioning, the prenatal period also includes initiation of psychological (in that case emotional) life of the prenatal child. The important factor of the man's complete subsequent development is prenatal memory which includes memories of the course of the pregnancy and birth (Turner, Jon RG, Troya GN, 1991). Mother passes the information to her prenatal child via both outer and inner environments: Through the outer environment, mother's voice is partly transferred (emotional speech expression) as well as the stimuli from the outer environment; through the inner environment - mother's speech and sounds and noises coming from the internal organs (heartbeat, breathing, the bowels, etc) and all the biochemical content from mother's organism via her blood.

Already in the prenatal period, basic trust or distrust towards the world is formed, based on the information which the prenatal child receives from the mother. According to Milaković's scheme of the "programming of the prenatal child" (Milaković, 1986), the mother teaches the prenatal child through her behavior, via "blood excitation" about everyday oscillations and models of frustration and satiation, which form the basis of its behavior and reactability in later periods of life. The term "blood excitation" implies the change of biochemical para-meters in the blood liquid under the influence of a range of factors resulting from mother's emotions, attitudes, states and behavior during pregnancy. Mother's emotional and neural transmitter input "tells" fetus how to feel during the influence of certain sounds, happenings, situations, activities, etc. The simplified explanation would be that prenatal learning takes place on the metabolic level, because the areas of the CNS (Central Nervous System) in charge of metabolic and vegetative control are fully developed, such as the mesodiencephalon, where integration centers of soma-psyche relation are situated.

There are so-called centers of sensors and detectors, centers for regulation of important functions of the organism, and in their vicinity there are regulators of hereditary schemes of reacting, impulses and activators of motivational behavior. The mechanism of this structure is very complex and it is based on the auto-control of the whole range of cybernetic models with excitatory and inhibitory cores, which, together with other autocontrol organs (from other body parts) create very strong systems interconnected with hormonal, transmitter and neural connections. These complex auto-control systems have a task of maintaining homeostasis in the organism, but their very complex mechanisms will not be discussed in this paper.

Via mechanisms structured in such a way, the prenatal child and the mother communicate via the placenta. The information is transferred from the mother's mesodiencephalon to the child's mesodiencephalon in a few seconds, following the principle of the transmitter (mother) and the receiver (child). 
One part of instinctive knowledge is genetically inherited, whereas the other part needs to be learned in the prenatal period in order to develop adaptational mechanisms which will provide "survival" during and after birth. These mechanisms are congenital, whereas the acquired ones are developed after birth.

It has been irrefutably proven that a human baby brings considerable experience of feelings and sensations from her/his intrauterine life, which significantly influence her/his psyche; ability to communicate with her/himself, parents and the surrounding world. Besides congenital reactions, innate reactions also develop in the prenatal period, depending on the inner environment (the mother's organism) and its interaction with the outer environment, to which reactions from the postnatal period of development are superimposed. Thus, both congenital and innate prenatal reactions represent the basis of behavior throughout the whole life. (Chamberlain1988, Sovilj, 1998, 2010, 2012; Brekhman, 2000, 2001; Turners, 2015).

Having in mind that both transgenerational and transpersonal mother-child-environment information are transferred, by memorizing and learning them, primary patterns of behavior are developed with a far reaching influence on behavior throughout life.

This paper will present one part of the results of the projects "Interdisciplinary research of verbal communication" with the subproject "Prenatal communication"; one of the goals being to study interconnections and interdependencies of transgenerational and transpersonal transfer of information and the possibility of their monitoring through the behavior of: the grandmother, the mother and the prenatal child (Epigenetics) and representation of basic typology of personality in the prenatal and adult population.

\section{RESULTS}

\subsection{Monitoring of transgenerational transfer of information}

The results of the following research were selected:

1.1 In order to monitor transgenerational transfer of information, we selected the responses from the constructed questionnaire which contained 62 questions which enabled comparison of the responses of mothers-daughters and their mothersgrandmothers. The questionnaire was completed by $\mathrm{N}=124$ mothers-daughters who had 1 or more children.

\begin{tabular}{|l|c|c|c|}
\hline & AM & SD & $M$ \\
\hline $\begin{array}{l}\text { Mothers - } \\
\text { grandmothers } \\
\text { Mothers - } \\
\text { daughters }\end{array}$ & 7.31 & 6.480 & 5 \\
\hline
\end{tabular}

Table 1. Length of contractions at birth in mothers-grandmothers and mothers-daughters 
Comparison of the length of contractions at birth showed no statistically significant differences between mothers-grandmothers and mothers-daughters i.e. between mothers- daughters ( $p>0.05)$ (Table 1$)$.

\begin{tabular}{|l|r|r|r|}
\hline & AM & SD & M \\
\hline $\begin{array}{l}\text { Mothers- } \\
\text { grandmothers }\end{array}$ & 9.3486 & 8.85728 & 8 \\
\hline $\begin{array}{l}\text { Mothers- } \\
\text { daughters }\end{array}$ & 10.88 & 9.656 & 10 \\
\hline
\end{tabular}

Table 2. Length of breastfeeding by mothers-grandmothers and mothers-daughters

Comparison of the length of breastfeeding between mothers-grandmothers and mothers-daughters showed no statistically significant differences ( $p>0.05)$ (Table 2 ).

\begin{tabular}{|c|l|l|}
\hline $\begin{array}{c}\text { Postpartum } \\
\text { mood }\end{array}$ & $\begin{array}{l}\text { Mothers - } \\
\text { grandmothers }\end{array}$ & $\begin{array}{l}\text { Mothers- } \\
\text { daughters }\end{array}$ \\
\hline Positive & $62-50 \%$ & $65-52.4 \%$ \\
\hline Neutral & $49-39.5 \%$ & $48-38.7 \%$ \\
\hline Negative & $13-10.5 \%$ & $11-8.9 \%$ \\
\hline
\end{tabular}

Table 3. Postpartum mood of mothers-grandmothers and mothers-daughters

Comparison of the mood immediately after birth of mothers-grandmothers and mothers-daughters showed no statistically significant differences (Table 3).

\begin{tabular}{|c|c|c|}
\hline $\begin{array}{l}\text { Baby's gender as } \\
\text { desired } \\
\text { yes }\end{array}$ & $\begin{array}{l}\text { Mothers - } \\
\text { grandmothers } \\
114-91.9 \%\end{array}$ & $\begin{array}{l}\text { Mothers- } \\
\text { daughters } \\
119-96 \%\end{array}$ \\
\hline no & $10-8.0 \%$ & $5-4 \%$ \\
\hline
\end{tabular}

Table 4. Was the born child of a desired gender

Comparison of the responses to the question whether the born child was of desired gender showed no statistically significant differences in the responses of mothersgrandmothers and mothers-daughters (Table 4).

The presented responses clearly indicate that information about the mother's distinctiveness, her behavior and attitudes are transferred trans-generationally, including physical, biological and psychological level. Further data processing within the project is ongoing. 


\section{2. Monitoring of information transpersonal transfer}

In order to monitor transpersonal information we compared the results of PHS (Prenatal hearing screening), the results of Spielberg Test 1 and 2 of pregnant women's anxiety degree ( $\mathrm{N}=123$ pregnant women).

2.1 Prenatal Hearing Screening (PHS) was developed at the IEPSP and is performed by the Sovilj-Ljubic Method [2], as a standard ultrasound examination with amplification of

a defined sound of $1500-4500 \mathrm{~Hz}$ frequency range, $90 \mathrm{~dB}$ intensity and $0.2 \mathrm{sec}$. duration by MIM tone generator, and monitoring of the values of the pulsatility index by measurement of the speed of blood flow in a cerebri media before and after sound amplification, $5 \mathrm{~cm}$. from the mother's belly, the pulsatility index ( $\mathrm{Pi}$ ) is measured, basic (before stimulation) Pib and reactability (after) Pir. In PHS there are two directions of reactability - increased (+) and decreased (-). PHS can be reliably applied from 27-31 gestation week. Normal PHS values range up to 14.6 (Pi index value), whereas higher values indicate present problems in the auditory system which can cause disorders in verbal development, behavior, learning and socialization. This paper will present only the results of reactability direction at the PHS examined on $\mathrm{N}=123$ pregnant women. At the application of PHS, 75\% of prenatal children reacted with increased (+) reactability, and $25 \%$ with decreased (-) reactability after the sound stimulus. These results indicate that bases of basic characteristics of the personality typology can be observed in the prenatal period.

Comparison of the obtained results of reactability with the results of a MBTI test (MyersBriggs Type Indicator personality inventory) related to the presence of extrovert and introvert persons in the global population indicates percentage congruence, i.e. $75 \%$ has basically extrovert and $25 \%$ has introvert typology of personality. Of course, this is basic predominant typology which additionally confirms that the mother and the community (collective consciousness) influence prenatal definition of basic typology of personality.

2.2 During the realization of the project, risk factors during pregnancy were monitored and recorded, including the anxiety degree by Spielberg Tests 1 and 2. Spielberg Anxiety Test 1 assesses the current condition of a pregnant woman, whereas Spielberg Test 2 assesses her condition within a longer period of time, i.e. the frequency of the listed conditions in her life.

We tested $\mathrm{N}=123$ pregnant women. The obtained results indicate $71 \%$ pregnant women showed high and moderate anxiety, and 29\% showed low anxiety (Spielberg Test 1). At Spielberg Test 2, 78.6\% pregnant women showed high and moderate anxiety, and $21.4 \%$ showed low anxiety throughout life (Verny and Weintraub, 2002; Janus 2001). The analysis of the given results indicates that transpersonal transfer of information motherchild is obvious and in the example of the anxiety degree and increased reactability of the prenatal child at PHS, there is positive correlation ( $r=0,039 \mathrm{p}<0.05)(1-71.4, \mathrm{C} 2-78.6: 75 \%$ PHS(+) (Graph 1). 


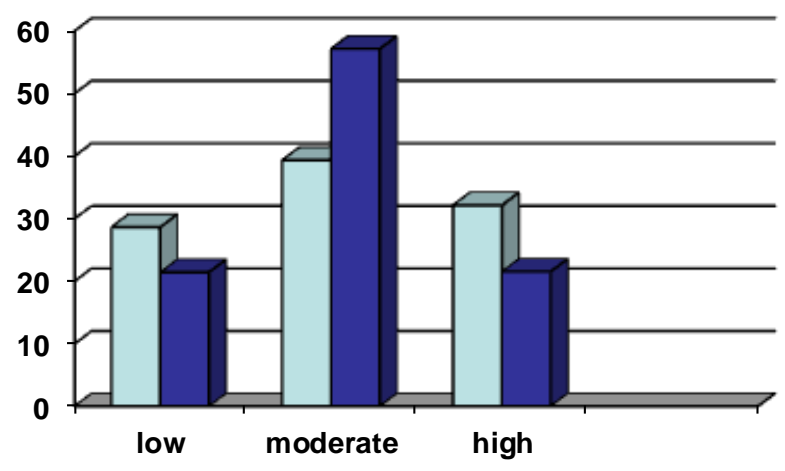

Graph 1. Anxiety degree of pregnant mothers - Spielberg test (light-C1, dark-C2)

Transpersonal transfer of information is best reflected in the following example. Have a look at the drawing of a mother who came to the IEPSP School of Educational Parenthood - Prenatal Education. She was 4 months pregnant when she made a drawing of her future child (Picture 1a) and below is an actual photo of her child (Picture 1b).

Picture 1a. Mother's drawing of a future child

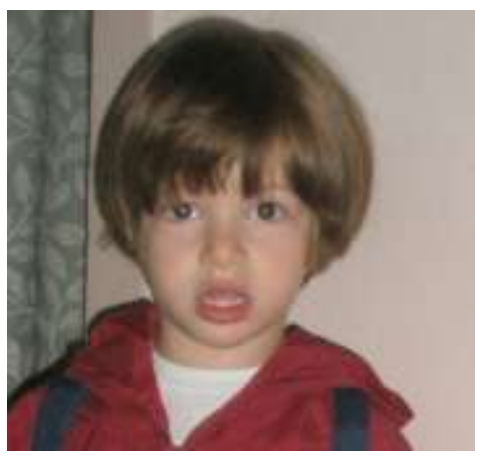

Picture $1 \mathrm{~b}$. The actual photo of the child

2.3 In order to perceive interconnections of emotions related to personal conception and deep prenatal traces fixed in memory, which are considered to be in the sphere of subconsciousness and can be evoked and analyzed through a drawing and 
types of listed emotions (Pictures 2, 3, 4), and the number of basically extrovert and introvert population, we designed an experiment "How I see and feel my conception". The experiment was carried out on an independent sample of $\mathrm{N}=174$ examinees with high education, aged 25-56. The experiment used a drawing made by examinees who were expected to draw on an blank sheet of A4 paper following a defined instruction: "Draw the moment when a sperm penetrated the egg and you were conceived and write down the first three emotions which appeared". Test time was limited to 3 minutes.

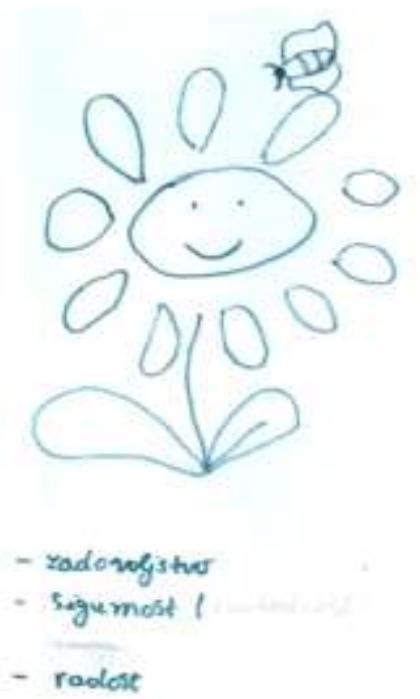

Picture 2. Positive Attitude: Contentment, safety, joy

The experiment used a drawing since it is the first human writing and a reflection of an idea, mental image and the concept of the world that surrounds the human being, and first attitude, understanding and sensation of that world. It is a reflection of the human's inner world, environment, inner state, content of fantasy, experience, imagination etc. and that

is why it represents such a powerful means of expression. A drawing is also a part of an individual's life picture i.e. her/his reflection coming from her/his hand and complex sensitivity. Therefore, it is a very powerful tool for integration of all the stated levels and is very frequently used in psychology. It is thought that a drawing opens one's soul. That is why a drawing was chosen for this subtle moment in one's life.

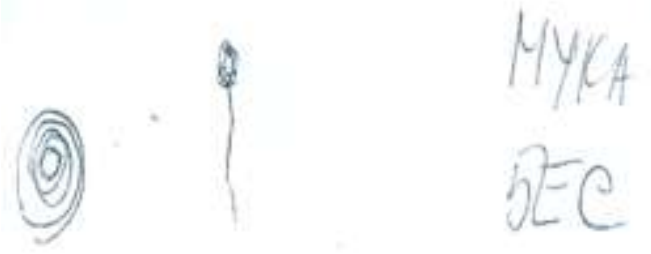

Picture 3. Negative Attitude: Fear, anguish, rage. 

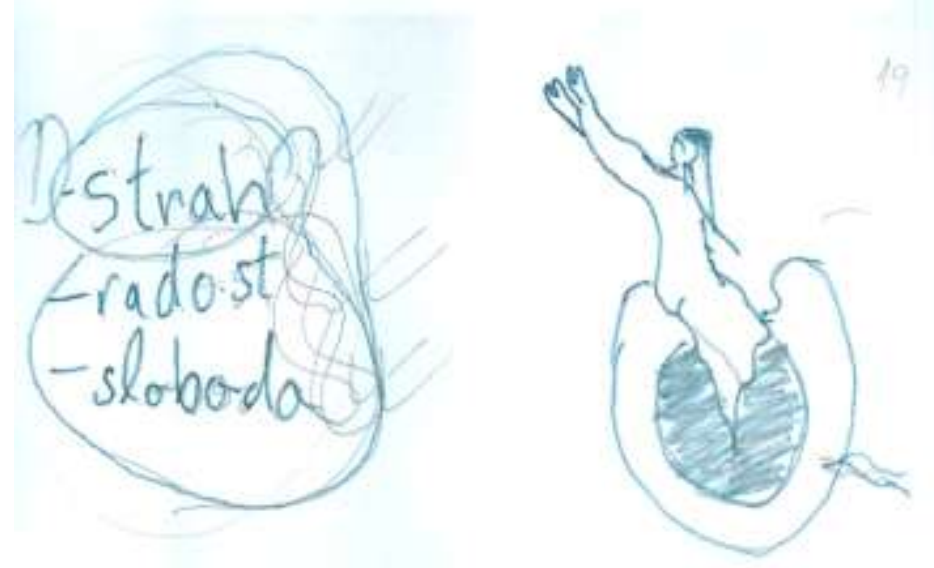

Picture 4. Mixed Attitude: Fear, joy, freedom

Analysis of the drawings according to the usage of the free surface of the paper indicate that:

\section{Examinees with positive emotions:}

$97 \%$ of examinees used the middle or the right side of the paper, which indicates optimistic attitude, openness to change, curiosity etc.

\section{Examinees with mixed emotions:}

$48 \%$ of examinees used the middle or the right side of the paper which indicates optimistic attitude, openness to change, curiosity etc.

$52 \%$ of examinees used the left side of the paper - which indicates that they are reserved, have a problem with establishing contact with others, pessimistic etc.

\section{Examinees with negative emotions:}

$23 \%$ of examinees used the middle or the right side of the paper which indicates openness, optimism, etc.

$77 \%$ of examinees used the left side of the paper which indicates reserved, a problem with establishing contact with others, pessimism etc.).

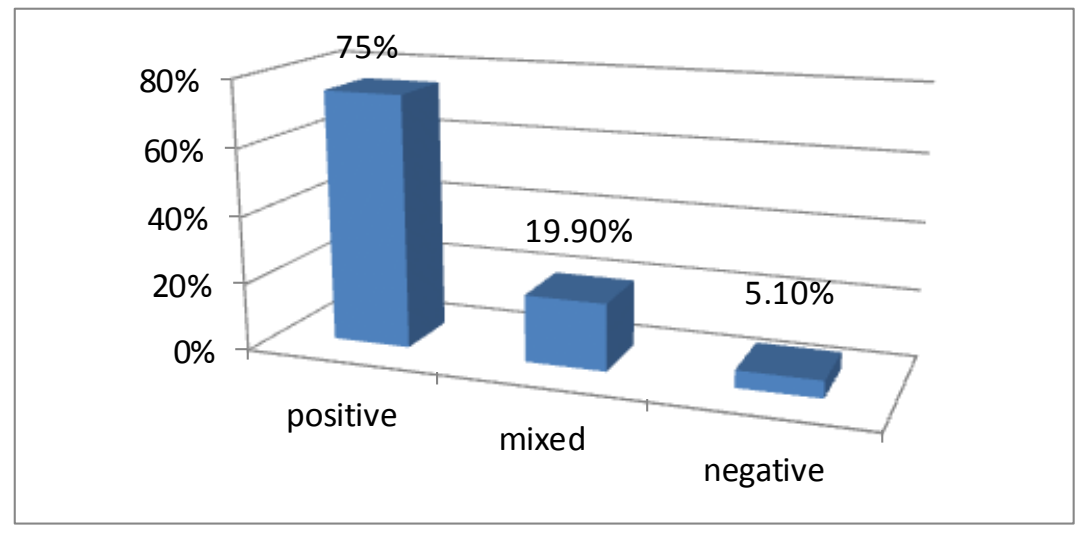

Graph 2. Distribution of emotions related to the moment of conception 
Results of the global analysis of drawings and types of expressed emotions indicate that $75 \%$ of examinees had positive emotions about the "moment of their conception", whereas $25 \%$ had mixed and negative emotions (Graph 2 and 3 ).

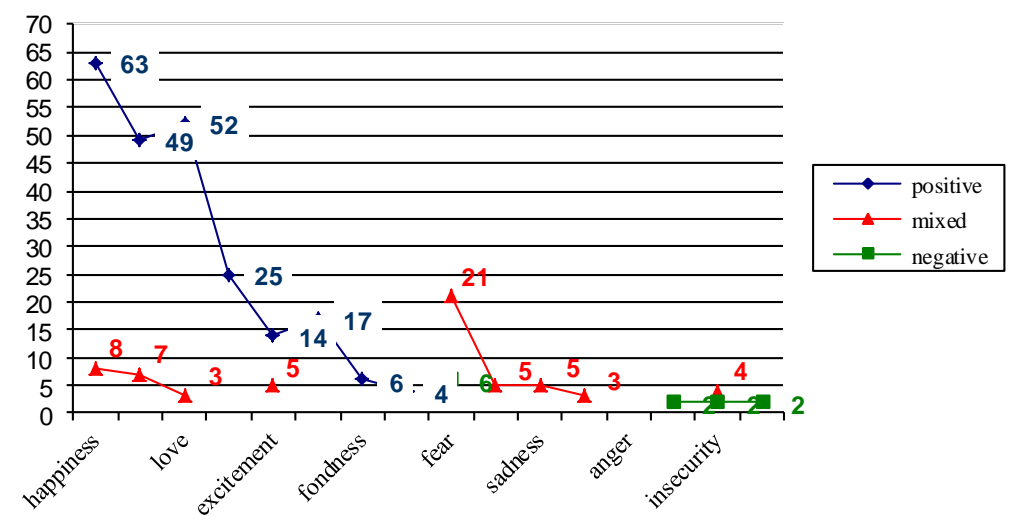

Graph 3. Distribution of types of emotions related to conception

The results of the analysis according to the criterion of the usage of free surface of the paper and emotions expressed are in full compliance, which confirmed accordance between visualization of the event and the emotional expression related to it.

Beside the presented research results, we also considered worldwide research dealing with types of personalities in the world population in order to observe complex multidimensional and a dynamic system of interactive connections in defining development and causal relations, communication and behavior of an individual and society. By application of the MBTI Test numerous authors analyzed typology of personality, adducing different number of personality types, depending on research goals, cultural, economic and social characteristics of the examined groups, etc. Tiegep P. Tiegep B.B. (1995) presented global data for the general world population, which indicate that $75 \%$ of the world population is basically extrovert and $25 \%$ introvert ((Myeps, 1980 , 1990, 2009; Myeps et al. 1998); Tiegep and Tiegep (1995)).

Tiegep and Tiegep (1995) present this percentage in relation to two basic typologies of personalities, indicating that the system of rewarding and word recognition is set to the extrovert value.

Unlike extrovert types, introverts mostly work in a quiet environment; enjoy working independently; reluctantly accept to be delegated; and, if it happens, offer very little information; work well without supervision; think seriously before taking action; sometimes share ideas but only when asked; are good listeners; remain calm under all types of pressure; and usually have essential knowledge.

Analyzing the results of the stated research it can be noted that the observed parameters unequivocally indicate, almost in all relations, the frequency rule of $75 \%: 25 \%$. 
Observing the obtained results, we can conclude that the emergent communication system

and behavior human to society contains transgenerational and transpersonal information and shows a proportional regularity, mostly $75 \%: 25 \%$ interactive connectivity:

behavior of the pregnant woman

(1) - increased reactability of the prenatal child to PHS;

(2) - positive attitude towards one's conception;

(3) representation of extrovert persons in the global world population.

Observing the percentage ratio of the stated parameters, it can be concluded that that an adult genetically passes typology of personality onto the descendant, and the mother's anxiety is then superimposed during pregnancy which consolidates the final ratio of extroverts and introverts in the general population.

\section{CONCLUSION}

For an in-depth understanding of the development of human consciousness and behavior, an holistic psycho-physiological and socio-biological approach should be applied from the prenatal period - conception, because each human being represents a multitude of hereditary traits of her/his ancestors and interaction with both narrower and wider environment. For this reason, it is necessary to educate the youngest generations about the importance and the way of collecting as well as appropriate usage of transpersonal and transgenerational information.

Due to transgenerational transfer of information, an individual is at the same time the "consequence" of previous conditions as well as states of his ancestors. If this fact is not perceived when considering the development of communication, then a Person (consequence) does not have essential insight into her/his own state and behavior, and even less in the state and behavior of others.

The results of the stated research indicate that the basic type of personality can already be established in the prenatal period. Obviously, a human being forms two types of perception under the influence of transgenerational hereditary genetic factors and heritable, epigenetic ones, which develop under the influence of the inner environment (the mother's behavior) and wider outer environment. This offers new possibilities of studying more subtle regularities of the onset and development of communication, behavior and learning of an individual and a society and promotion of their development.

Observing the emergent system of human and society i.e. their communication and behavior, both individual and social, we note that the influences from the micro level of the system - an individual, on the macro level - society, result from interactions of its parts. This dynamic interaction creates the feedback which forms future states of the system, thus providing evolution and permanence of this emergent system as an expression of an interaction and integration of individual psycho-physiological and social socio-biological. This standpoint requires more subtle studies of possibilities of promotion of human communication and behavior, since the basic type of personality already can be 
detected from the prenatal period, thus offering a framework for understanding individual differences and offering a possibility for an optimal dynamic model of individual and social development. The stated regularities can be signposts for the development of adequate and timely models for better interpersonal communication and behavior, through a higher degree of self-knowledge, self-respect, respect of others and creativity.

At the same time, results confirm the statements that collective consciousness influences individual consciousness and vice versa, but also far more than that. Having in mind peculiarities of extrovert and introvert persons, it is to be expected that prenatal training and work with pregnant women on raising consciousness about the necessity of establishing and maintaining positive moods (attitudes) in pregnancy, would result in the balance of extrovert and introvert reactions and decrease aggressiveness in all fields of human activity on the global plan and provide more adequate reactability in different life situations; higher degree of creativity and tolerance; as well as a higher level of personal and collective responsibility.

Experts dealing with human development, health and education need to raise the level of their professional competence in order to gain insight into overall potentials and development of a person, from the moment of conception, using holistic approaches to adequately look after the development, health and education of posterity and thereby the future of the human race and our planet.

Note: This paper is a result of the projects "Interdisciplinary Research of Speech and Language Resources of Serbian Language" and "Protocol for Optimization of Children's Learning Potentials" financed by the Ministry of Science and Technological Development of the Republic of Serbia.

\section{References}

Bpekhman, G.I. (2000). The conception of the multiple level co-ordinated action between the mother and her unborn child: The methodological approach and the methods of research. ISPPM Congress, Cagliari, Sardinia, June 22-24, 2000, pp. 37-45.

Brekhman, G.I. (2001). The conception of the wave multiple-level interaction between the mother and her unborn child. Int. J. of Prenatal and Perinatal Psychology and Medicine, 13, (1/2), 17-25.

Bakhmutsky, A., Brekhman, G., Bukreev, V. (2010). Latent roots of violence: unconscious motives, mentality, ways to prevent. Council of Scientists' House, Haifa.

Chamberlain, D. (1988). Babies Remember Birth. New York: Ballantine Books.

Dent, E.B. (1999). Complexity Science: a Worldview Shift. Emergence, 1 (4), 5-19.

Grof, S. (1986). Beyond the Brain: Birth, Death and Transcendence in Psychotherapy, State University of New York.

Kovalenko, N.P. (2007). Perinatal Psychology. Izdatelstvo MGU, Moskva (in Russian).

Verny, T., Weintraub, P. (2002). Tomorrow's Baby. New York: Simon \& Schuster. 
Janus, L. (2001). The Enduring Effects of Prenatal Experience. Heidelberg: Mattes.

Milaković, I. (1986). Where mother and child were alone. Svijetlost: Sarajevo, ZUNS: Belgrade (In Serbian).

Myers, I.B., McCaulley, M.H., Quenk, N.L., Hammer, A.L., Mitchell, W.D. (2009). MBTI Step III Manual: Exploring Personality Development Using the Myers-Briggs Type Indicator Instrument. Consulting Psychologists Press.

Myers, I.B. (1990). Introduction to Type: A Description of the Theory and Applications of the Myers-Briggs Type Indicator. Center for Applications of Psychological Type Inc.

Myers, I.B. (1980). Gifts Differing: Understanding Personality Type. Davies-Black Publishing; Reprint edition.

Myers, I.B., McCaulley, M.H., Quenk, N., Hammer, A. (1998). MBTI Handbook: A Guide to the development and use of the Myers-Briggs Type Indicator Consulting Psychologists Press, 3 rd edition.

Johnson, D.L., Wiebe, J.S., Gold, S.M., Andreasen, N.C. (1999). Cerebral blood flow and personality: A positron emission tomography study. American Journal of Psychiatry, 156 (2): 2527 .

Radičević, Z., Vujović, M., Jeličić, Lj., Sovilj, M. (2008). Comparative findings of voice and speech: language processing at an early ontogenetic age in quantitative EEG mapping, Experimental Brain Research. Vol. 184; 529-532

Selaković, M., Sovilj, M., Adamović, T., Bojović, K., Nenadović, V. (2012). Protocol of prevention and treatment of verbal communication and learning in children from 0 to 3 years. Editor. Sovilj M. 2012, LAAC, IEPSP, Belgrade (In Serbian).

Sovilj, M., Ljubić, A., Milenković, V., Đoković, S. (1992). Possibilities of Prenatal Research of Reaction to Sound in Fetus with Congenital Infections. 1992 Collection of abridged works, $X$ Jubilee Symposium - Section for perinatal medicine. Book of Abstracts, S.L.D., Belgrade, 17-18.

Sovilj, M. (1998)., Downward Processes in the Perception Representation Mechanisms, Sound, Hearing and Consciousness, Napoly, pp. 487-493.

Sovilj, M., Dobrijević, Lj., Radičević, Z. (2008). Comparative findings of voice and speech: language processing at an early ontogenetic age in quantitative EEG mapping, Experimental Brain Research, Volume: 184, Issue: 4, Pages: 529-532.

Sovilj, M. (2010). Prenatal development of hearing and verbal communication. Third European Congress of Early Prevention in Children with Verbal Communication Disorders. 2010, Editors Skanavis M., Sovilj M., Bojanova V., Olympia, Greece, October 22-24, Abstracts and Program, pp. 64-65.

Sovilj, M. (2012). Prenatal memory and learning. MD-Medical Data, UDK: 59.953-053.13; 612.647, 159.953-053.13, ID BROJ: 193387532, issn 1821-1585, 2012; 4(3): 259-266.

Sovilj, M. (2013): Bases of (prenatal) communication. Conference Speech and Language. 4th International Conference on Fundamental and Applied Aspects of Speech and Language, October 25th-26th, 2013, Belgrade, Serbia, Proceedings, (Eds): Sovilj M., Subotić, M., LAAC, IEPSP, Belgrade, ISBN 978-86-81879-45-0, pp. 46-49. 
Shadrikov, V. D. (2002). Introduction in general psychology: emotions and senses. Logos, Moskva (In Russian).

Sharma, R.S. (1980). Clothing behavior, personality, and values: A correlational study.

Psychological Studies, 25, 137-142.

Tieger, P., Tieger, B.B. (1995). Do what you are: discover the perfect career for you through the secrets of personality type. Boston: Little, Brown.

Turner, Jon RG, Troya GN (1991) Prebirth Memory Therapy Int..J. Prenatal and Perinatal Studies, pp 111-117.

Turner, Jon RG, Troya. G. N (2015). How Prenatal Psychic Trauma and Communication Works in Whole-Self Prebirth Psychology Proceedings 1st International Congress on Psychic Trauma: Prenatal, Perinatal \& Postnatal Aspects May 15-16, 2015 Crown Plaza Hotel Belgrade, Serbia, www.iefpg.org.rs.Konferenceje.

Uskoković, V. (2006). Principles of holistic sciences of future. Research Center - ICNT, Belgrade (In Serbian) Vilynas, V.K. (1990). Psychological mechanisms of human motivation. MGU, Moskva (In Russian).

Vilynas, V.K. (2008). Psychology of emotions. Izdatel-Mos-Piter, (Seriя «Hrestomatiя po psihologii») (In Russian).

Zeidner, M., Roberts, R. (2008). The science of emotional intelligence: Knowns and unknowns. Cambridge, MA: Oxford University Press. 